\title{
Cost optimization for public school building projects during design stage using value engineering
}

\author{
Afrah Hassan ${ }^{1, *}$ and Majid Yahya $^{1}$ \\ ${ }^{1}$ Building and Construction Engineering Department, University of Technology, Baghdad, Iraq.
}

\begin{abstract}
During the past ten years, various systems of building components have been applied in public school projects in Iraq, with no systematic method used for selection and evaluation, but only based on the designer's experience. This paper displays evaluation and selection techniques based on value engineering methodology to find the optimal cost for school building projects in Iraq during design stage. The most important criteria for performance, constructability and sustainability criteria, which based on the Leadership in Energy and Environment Design used in this assessment were obtained from a survey of 49 professional designers and consultants, adoption of the Super Decisions Software Program, which uses analytical hierarchy process (AHP) for determining the relative importance of the main criteria and subcriteria, that allows the decision-makers to evaluate the suitable alternatives of design for the external wall system in Iraq's school buildings was built.
\end{abstract}

\section{Optimizing building cost}

When making a decision to optimize the design of the building, one must specify the various criteria to judge the optimized solution. The likelihood of any one solution being the best of each criterion is remote. In practice, therefore, one criterion is usually adapted and this on the basis of the use of money, becomes the objective of value maximizing with minimum cost.

There are three elements common in the optimization:

1 . The set of alternatives.

2. The value system, which assigns a numerical value for "goodness" so that means "the best" can be known.

3 . The means calculating the numerical value of each alternative and comparing this value with each other.

Every owner would like to ensure that many available alternatives have been thoroughly investigated and that alternative selected is the most efficient and economical both on short-term and long-term basis. To accomplish this, the design team performs life-cycle cost analysis, and value engineering as well as model analysis.

\subsection{Value engineering applied to design}

The VE program should be established at a management level where it can effectively challenge design criteria, including established standards, and where it can have access to operational and maintenance cost. This VE program should supplement present method and provide better information on which to make design decisions.

Value engineering studies applied at the design phase of project will realize a great cost saving in practice; it is this stage that receives the most attention. VE plays an important role in both preliminary and detailed design. Preliminary design improvements will probably contribute greatest to initial cost of savings. Whereas VE application to detailed design can eliminate design failure and address itself to maintenance aspects of an engineering system.

Figure 1. shows the decisions that have the significant influence on the expense of funds during the life cycle of the facility. Owners and consultants are key decision makers. To ensure the optimum results, it is necessary to involve the owner and the consultant in the professional assessment process.

With regard to the total costs of the facility, consultant fees represent the little expenditure for all initial costs. Consultants' decisions affect about $50 \%$ of the total costs of the facility. Therefore, optimal results can be expected when resources are allocated to environmental equipment at an early stage of the design process, focusing on the impact of the owner and consultant.

\footnotetext{
* Corresponding author: bce.41593@uotechnology.edu.iq
} 


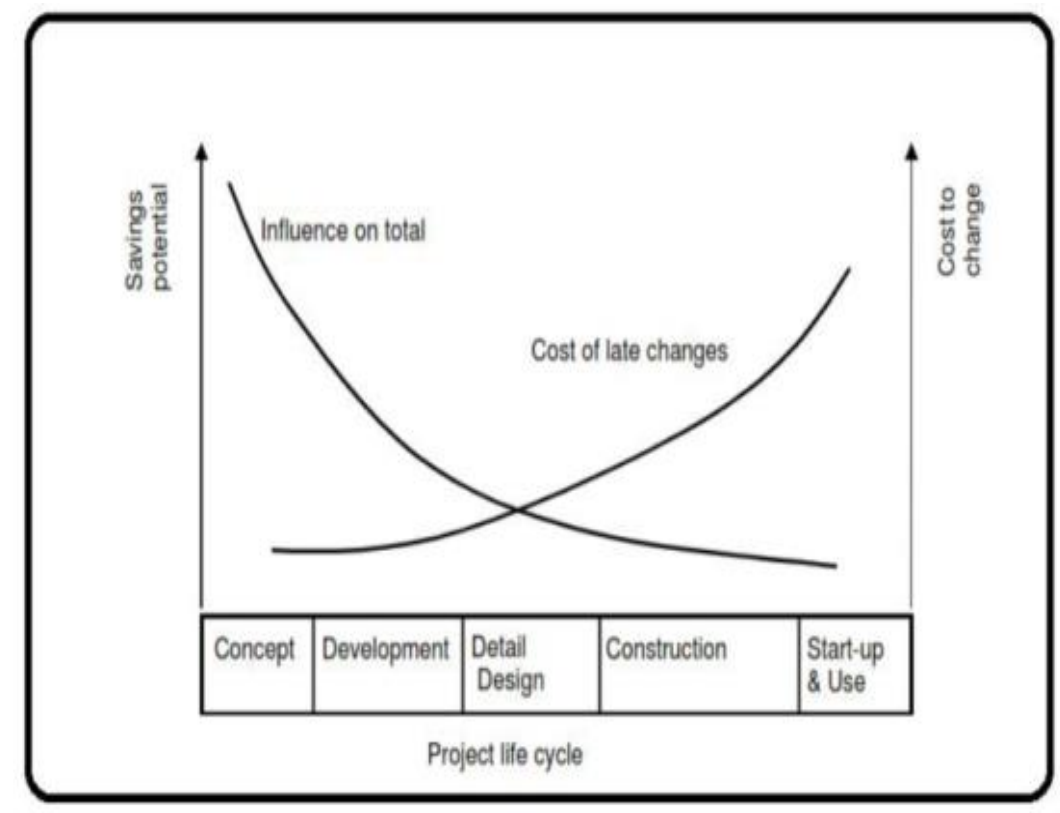

Fig. 1. Cost savings potential over project duration

\subsection{Value index}

Dell 'Isola defines the Value Index as the result of the relationship between relative importance and relative cost. This output plays an important role in the application of the value engineering methodology as it will be a guide to the elements for which value engineering is applied and calculated by the following equations:

Value Index $=\frac{\text { Relative importance }}{\text { Relative cost }}$

Value Index $=\frac{(\text { Function }+ \text { Quality })}{\text { Cost }}$

The critical value of the Value Index that can be used to determine the good economic value of the product or service is (1). If the Value Index is greater than or equal to (1) it represents a good economic value, and if the value index is less than (1) it represents a weak economic value.

\subsection{Value engineering methodology (job plan)}

The Job Plan consists of several stages or phases. There is no general agreement on the number or titles of these phases despite the fact that regardless of the terms used or number of stages (which varies from 5 to 8 depending on the source of Job Plan), they all share in the goal of VE studies. In general, this goal is simply to put forward a standard methodology of analysis that is broken down into a series of steps to assist the user in its application and to improve the decision making process for systematically displaying all facts and ideas necessary for an effective analysis.

General overview of Job Plans indicates that at a minimum, any Job Plan must be comprised of the following phases as perceived by the researcher:

1- Information phase.

2- Function Analysis phase.

3- Creative phase.

4- Analytical / Evaluation phase.

5- Development phase.

\subsubsection{Information phase}

This is the first phase of the value engineering methodology, in which the system under study is thoroughly understood in all its formal, functional and practical aspects. It collects as much information as possible about the product or system under study and its components (for the current design). The designer, the client and the project manager are required to provide the necessary information, including the following:

1. Design criteria (constructability, conditioning and cooling, load planning)

2. Design calculations

3. Site conditions (topography, soil conditions, surrounding areas,)

4. Detailed design drawings

5. Technical Specifications

6. Operating schedule and its estimated costs

7. The maintenance schedule and the estimated costs

8. Table of power consumption rate

9. Construction Cost Estimates (Bill of Quantities)

10. Services available. 


\subsubsection{Function Analysis phase}

In the functional analysis, it is necessary to reach inside the item details by analyzing the components of the system under study and the knowledge of basic and secondary functions.

The functional analysis will be completed as follows:

1. Identify functions.

2. Functions classification.

3. Link the functions to diagram (FAST Diagram).

4. Select which functions can be improved.

\subsubsection{Identify functions}

The application of a function in a value engineering study is a function analysis, the project or product is evaluated by identifying what the item does. The verb is an action verb and the noun, a measurable noun, for example: a light bulb function is a lighting area.

\subsubsection{Functions classification}

The classifications of function includes the following:

1. Basic Function: Is that which is essential to the performance of a user function, or the function describing the primary utilitarian characteristic of a product or design to fulfil a user requirement.

2. Required Secondary Function: A required secondary function is any function that must be achieved to meet codes, standards, or mandatory owner requirements.

3. Secondary Function: If secondary functions are removed from the design, both the basic and required secondary functions can be realized. As such, their worth is zero.

\subsubsection{Functional Analysis Systems Technique (FAST) Diagram}

Using FAST involves a function block diagram based on answers to what? why? What?

FAST is an effective way to get good answers for three logical reasoning questions:

What is the problem?

Why is the solution necessary?

How can the solution be achieved?

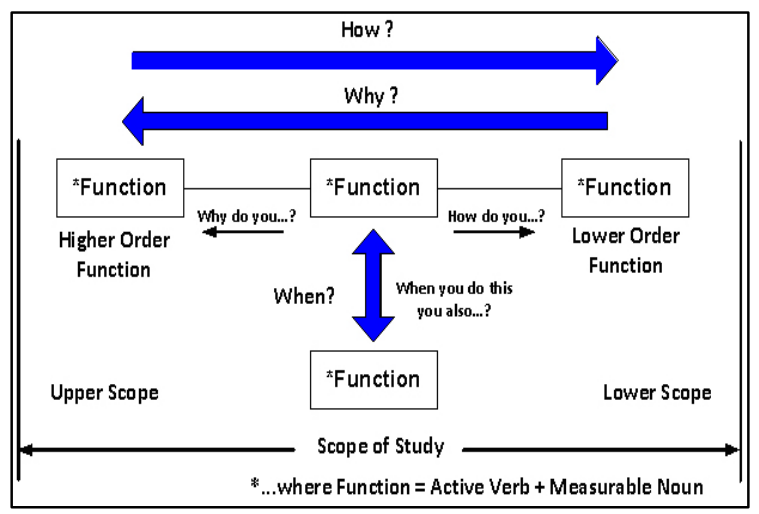

Fig. 2. FAST Diagram.

\subsubsection{Creative phase}

The goal of this phase is to generate ideas for alternative solutions to the basic function of the item.

The traditional alternatives are eliminated through the use of all the tools of creative knowledge to solve the problem, including brainstorming sessions and conferences to solve problems used to create an open space of free flow of information and it generates a list of idea.

in the creative phase are not seen as appropriate.

\subsubsection{Evaluation phase}

In this phase, the team examine creative phase and evaluate the feasibility of each idea by identifying its advantages and disadvantages.

In the order of ideas, the following should be considered [22]:

- Did you meet the requirements of aesthetics, performance, quality and reliability?

- Does the proposed idea meet the required functional requirements?

- Will a redesign or excessive delay be created for the project?

- Is there an improvement in operation and maintenance?

- Will life cycle cost savings be achieved?

- Does the idea have a reasonable chance of acceptance and implementation?

- Was the proposed design used in the past?

- Does the idea fundamentally affect the aesthetics of the building or project?

Top ideas rated are selected by the team.

\subsubsection{Development phase}

At the development phase, the best ideas from the evaluation phase are developed into proposals that can be applied. The team develops initial designs, life cycle cost, comparisons of original designs and suggested alternative ideas.

During this phase, the team's technical expertise becomes very important.

Often, it is necessary to consult external experts, vendors and reference sources for additional assessment information before developing available alternatives.

\subsubsection{Life-Cycle Cost (LCC)}

LCC is a method used to compare and evaluate the total cost of competition solutions to meet identical functions based on the expected life of the facility or product to be obtained. In conducting a value study, the LCC analysis is what was carried out in the development phase of the VE Plan to select the least expensive alternative.

The LCC relates to total construction costs over the economic life of the project.

Figure 2 shows how total building costs were incurred. 
There are many ways to bring life cycle costs to a comparable time base; present value, interest rate and annual equivalent.

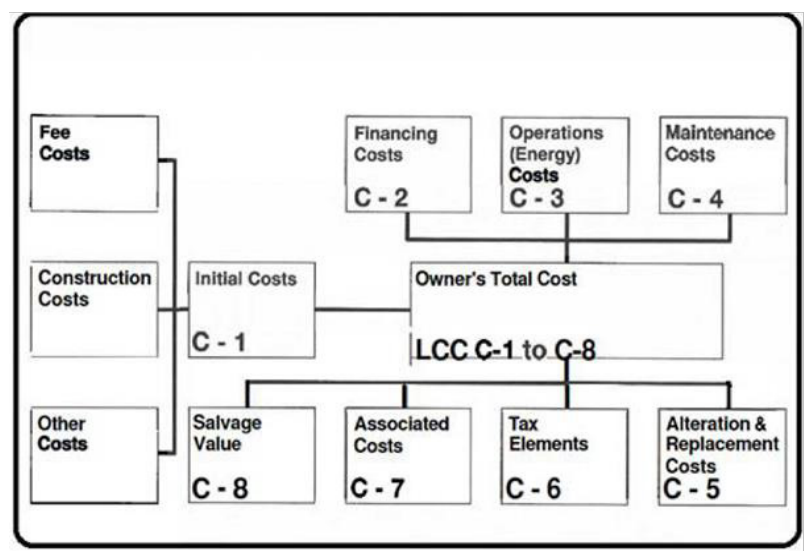

Fig.3. Life cycle cost elements

\subsubsection{Weighted Evaluation}

As a last step, economic cost data should be mitigated with human factors such as comfort, appearance, performance, safety and costs (initial operation, maintenance, replacement and rescue).

A weighted evaluation is used to formalize the process. A weighted assessment ensures optimal decisions. Good decisions are made by properly focusing on all criteria. It is important during the evaluation process to discuss and weigh the following areas:

A) Needs versus desires

B) Important vs. unimportant

C) Designing the exchange for the required jobs

The weighted evaluation procedure has been divided into two parts: the criteria -weighted process and analysis matrix. The weighted process of criteria is designed to isolate important criteria and establish them weight and / or relative importance. Figure 4 shows a typical weighted valuation for example of a car purchase.

\section{Case study for value engineering application in schools design}

The researcher selected steel-structure school building to consider as the case study for this research, which was implemented by the Iraqi Ministry of Education / Directorate General for school buildings in the previous years and some have been under implementation, and will be the evaluation of a suitable alternatives for selection model to achieve optimal cost for constructional parts of the building.

From the researcher point of view an important part of the building was studied in terms of cost, different construction methods, materials and other basic functions.

Super-structure (primary elements) was of a greater significance than other parts of buildings that consist the frame, exterior and interior walls, exterior \& interior finishes, roofs for the application of the Value Engineering methodology.

Any job plan must consist of the following phases as envisioned by the researcher:

1. Information phase.

2. Creative phase

3. Analytical phase.

4. Evaluation and development.

5. Recommendation phase.

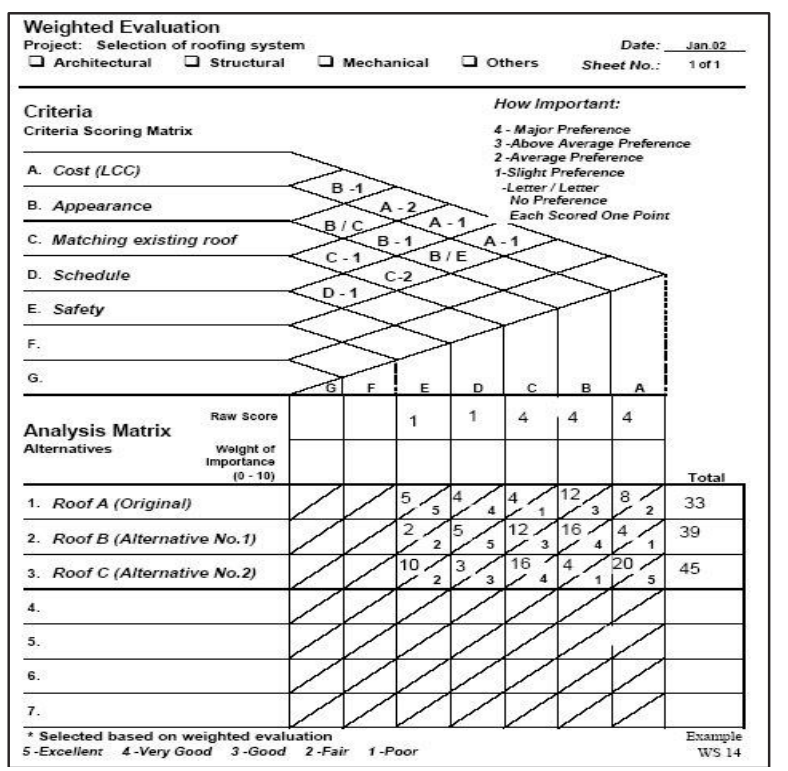

Fig. 4. Weighted evaluation matrix

\subsection{General information about the building}

Brief of description as follows:

- A12 class's school with the area of 1400 square meters.

- The yard area is equal to 3000 square meters in average (50x60 or $40 \times 75) \mathrm{m}^{2}$.

- $20 \mathrm{~cm}$ prefabricated light weight concrete fence.

- The school has been designed for three stories (ground +1 st. +2 nd floor), as shown in the Fig.5.

The Client, Ministry of Education intends to further develop the 12 classes' schools in Baghdad city, seeking for the PC contractor who has the ability for the rapid installation.

Contract is on a Lump-sum basis due to the Bill of quantities, and the itemized break down of the lump sum price- unpriced cleared by weight factor chart.

According to a contract signed between the Engineering Consultancy Bureau of AL-Nahrain University and The General Directorate of School Projects for checking of the 12 Classroom Primary School Steel Structure. 


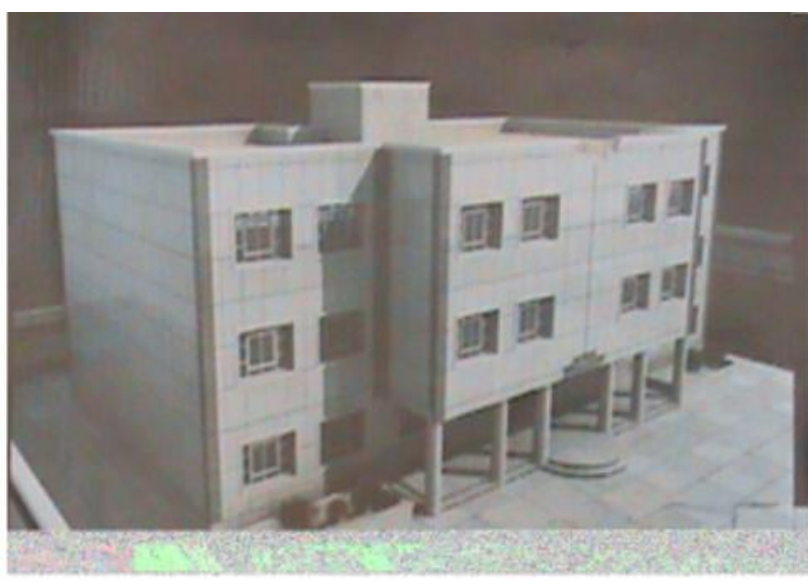

Fig.5 The shape of school building.

\subsection{Proposal alternatives for external walls non- load-bearing of School building}

All required data and information in this proposal were derived or taken from the bill of quantities for steel structure schools (records, calculations, documentation, and opinions of specialist engineers).

The current system used to provide external walls for the building is a metal-framed sandwich panel with insulation system.

\subsubsection{Information phase}

External walls for the steel-structure school building constructs from (Composite material, Sandwich panel, studs and high density, moisture, scratch and heat resist Gypsum board) as indicated in the drawings and finishing material table as shown in Fig. 6.

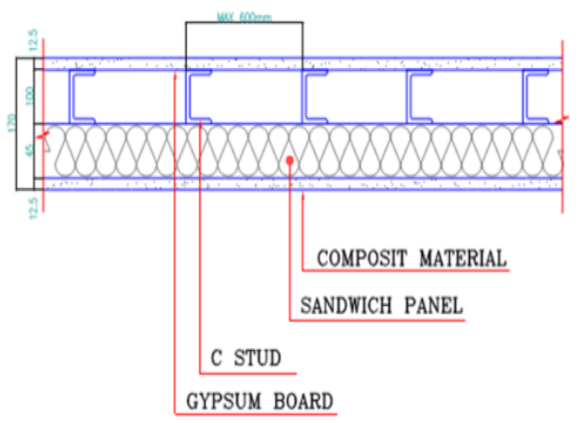

Fig. 6. External wall section.

\subsubsection{Functional Analysis Phase}

The researcher evaluated building components to search for any potential changes for the items of the project. Next, a functional analysis was performed for the exterior wall system for the current system (composite materials), as shown in Table 1
Table 1 Functional analysis for current system

\begin{tabular}{|c|c|c|c|c|}
\hline \multicolumn{4}{|c|}{$\begin{array}{c}\text { Project: Steel-structure school building } \\
\text { Exterior wall system }\end{array}$} & \multirow{2}{*}{$\begin{array}{c}\text { Item: } \\
\text { Original } \\
\text { Cost per } \\
\mathrm{m}^{2}(\$)\end{array}$} \\
\hline NO. & Component & $\begin{array}{l}\text { Function } \\
\text { Verb Noun }\end{array}$ & $\begin{array}{l}\text { Function } \\
\text { Level }\end{array}$ & \\
\hline 1 & $\begin{array}{c}\text { C studs } \\
(100 \mathrm{~mm} \\
\text { thickness })\end{array}$ & Framing & Basic & 15 \\
\hline 2 & $\begin{array}{c}\text { Sandwich } \\
\text { panel( } 45 \mathrm{~mm} \\
\text { thickness })\end{array}$ & $\begin{array}{l}\text { Thermal } \\
\text { comfort }\end{array}$ & Basic & 10 \\
\hline 3 & $\begin{array}{c}\text { Gypsum } \\
\text { board high } \\
\text { density, } \\
\text { moisture } 2 \\
\text { Layer } 12.5 \\
\text { mm }\end{array}$ & Sheathing & Secondary & 17 \\
\hline
\end{tabular}

\subsubsection{Speculative Phase}

Brainstorming sessions were led by VE team. Several ideas were recorded for various aspects of the external walls for the building. Table shows a list of some of the ideas for the exterior wall system of the building; these proposals are:

1. Solid brick wall Brick cavity wall

2. Solid block wall

3. Precast concrete wall panel

4. Light Weight Block Wall

Table 2. Brainstorming list of Exterior wall system proposals

\begin{tabular}{|c|c|c|}
\hline \multicolumn{2}{|c|}{$\begin{array}{l}\text { Study Title: Exterior wall } \\
\text { system }\end{array}$} & $\begin{array}{l}\text { Team: } \\
\text { VE team }\end{array}$ \\
\hline \multicolumn{3}{|c|}{$\begin{array}{l}\text { Generate as many ideas as possible to fulfil the } \\
\text { basic function of the item understudy. Do not } \\
\text { evaluate the ideas here at all. List everything, } \\
\text { judge later. }\end{array}$} \\
\hline $\mathrm{NO}$ & System & $\begin{array}{r}\text { System } \\
\text { assemblies }\end{array}$ \\
\hline 1 & Brick cavity wall & $\begin{array}{l}\text { Consist of brick } \\
\text { masonry units. All } \\
\text { joints are filled } \\
\text { with mortar. }\end{array}$ \\
\hline 2 & $\begin{array}{l}\text { Light Weight Block } \\
\text { Wall } \\
\text { (THERMOSTON)E }\end{array}$ & $\begin{array}{l}\text { Block masonry } \\
\text { units. } \\
\text { All joints are filled } \\
\text { with mortar. }\end{array}$ \\
\hline 3 & $\begin{array}{l}\text { Precast concrete wall } \\
\text { panel }\end{array}$ & $\begin{array}{l}\text { Precast concrete } \\
\text { wall panels, cured } \\
\text { off-site. }\end{array}$ \\
\hline
\end{tabular}

\subsubsection{Analytical Phase}

The first part of this phase was used to refine the list of ideas. Possible ideas were identified and retained, while other ideas were ignored. Ideas with potential were studied more closely, so that they could be incorporated with their advantages and disadvantages, as shown in Table 3. 
Table 3 Advantages and disadvantages of proposed systems for Exterior Wall.

\begin{tabular}{|c|c|c|c|}
\hline No & Idea & Advantages & Disadvantages \\
\hline 1 & $\begin{array}{c}\text { Metal-framed sandwich } \\
\text { panel }\end{array}$ & $\begin{array}{c}\text { Better aesthetics } \\
\text { Thermal comfort }\end{array}$ & $\begin{array}{c}\text { Require skilled labor } \\
\text { High initial cost of material } \\
\text { Long construction time } \\
\text { Frequent maintenance }\end{array}$ \\
\hline 2 & Precast concrete wall & $\begin{array}{c}\text { Best aesthetics } \\
\text { Permanent materials } \\
\text { Fast construction time } \\
\text { Best quality control }\end{array}$ & $\begin{array}{c}\text { Transportation arrangement } \\
\text { Thermal heat gain }\end{array}$ \\
\hline 3 & Brick cavity wall & $\begin{array}{c}\text { Less maintenance } \\
\text { Low initial cost } \\
\text { Materials are available }\end{array}$ & $\begin{array}{c}\text { Large material wastage } \\
\text { Large construction time }\end{array}$ \\
\hline \multirow{3}{*}{4} & Light Weight Block & $\begin{array}{c}\text { Better aesthetics } \\
\text { Durable material } \\
\text { Thermal comfort } \\
\text { Acoustic insulation }\end{array}$ & Transportation arrangement \\
& & Large material wastage \\
& & & \\
\hline
\end{tabular}

\subsubsection{Development Phase}

The best ideas and proposal alternatives are used to reach the optimal decision in the following steps:

\subsubsection{Identifying the main criteria and sub-criteria for external wall systems of school building design}

Three basic concepts of building design were adopted as follows:

a). There are several concepts concerning the constructability which can be applied in the design and configuration, these concepts are aimed at:

1. Choose the design to enable an efficient creation process.

2. Use of parts, materials and work tools available locally as much as possible.

3. Flexibility: Going to determine the design desired results and is not required for ways to reach those results so as to give flexibility to the port to get to the result in the best way.

4. Skills of available labor: The absence of one of two factors, the availability of labor or degree of skilled labor will be very expensive, so the results should be the introduction of this factor in the early design stages.

There are requirements of the performance in the design phase.

b). Performance means "interest of origin after the completion of its creation." So there are several requirements to improve the quality of performance to be considered during the design phase and these requirements:

1-Durability

It is the ability of an item, product or building to maintain its intended function of life expectancy with the intended maintenance levels in the intended use conditions.

2- Safety

Safety is, in any case, of great importance in all stages of the life cycle of the building and starting from the design stage. The terms of danger and risk are frequently used when analyzing the subject of safety. The Hazard: is the recipe for the product that can lead to harmful results the Risk: It is the possibility of injury because of the hazard when the product is turned on by the user.

3- Maintainability

It can be defined as "the function of the design and installation characteristics that affect the programme or under environmental operating conditions Maintenance". c). At present, strategies have emerged to achieve high performance in the major areas of environmental health and to incorporate the principles of sustainability into the development of construction elements. In 1993 a nonprofit organization was established that adopted a voluntary program called "Leadership in the environment and energy design". From it Indoor environmental quality, including control of thermal and acoustic systems and finally the criteria of use of materials and resources, including emphasis on the use of local materials and construction waste management.

\subsubsection{Assessment of criteria importance (Weights)}

For the purpose of determining the importance of criteria (weights), and also to choose the best alternative from a number of alternative proposals, this research has relied on the field questionnaire, and the improved AHP program (Analytic Hierarchy Process) method is used to determine the weight for different indicators (criteria). The program will identify these important criteria through the pairwise comparison between criteria; as will be explained later, for access to indicators (indexes) for the comparison.

Where selected sample respondents are asked to assess the importance of criteria for buildings design according to a scale ranging from 9 to 1 ( 9 degree $=$ high importance of criterion) 1 degree $=$ low importance of the criterion

\subsubsection{Build an AHP decision model}

Analytic Hierarchy Process (AHP) is one of the most versatile decision-making methods and is one of the most 
used algorithms for selecting the optimal alternative. This method was designed by Professor Thomas L. Saaty at the University of Pittsburgh in the mid-1970s and can be defined as a method of arranging decision alternatives and selecting the best alternative when a decision maker has multiple objectives or criteria on which the decision is based. While Wang (Et. 2004) defines it as the decision-making tool that analyzes or disassembles the complex problem into a multi-level hierarchical structure of goal, criteria and alternatives. The basic idea of this approach is to transform objective estimates of relative importance into a set of degrees or total weights. By having this method of fundamental property, which is based on the Pairwise Comparison, it complements the various quantitative and qualitative measures to combine them into one comprehensive degree that expresses the order of the alternative between a set of decision alternatives.

\subsubsection{Use Super Decisions Software to build AHP decision model}

A Super Decisions model consists of clusters of elements (or nodes) arranged in levels. The simplest hierarchical model has nodes connected by lines in them, the clusters contain goal, criteria elements and the alternatives of the decision as shown in Figure 7.

\subsubsection{Weighted evaluation matrix Using Super Decisions Software (AHP)}

After the results of the questionnaire are analyzed, the weights of criteria are specified for external wall systems of school building design; that will be found by using a program (AHP), which will make pair comparisons between criteria depending on the values of arithmetic mean for criteria.

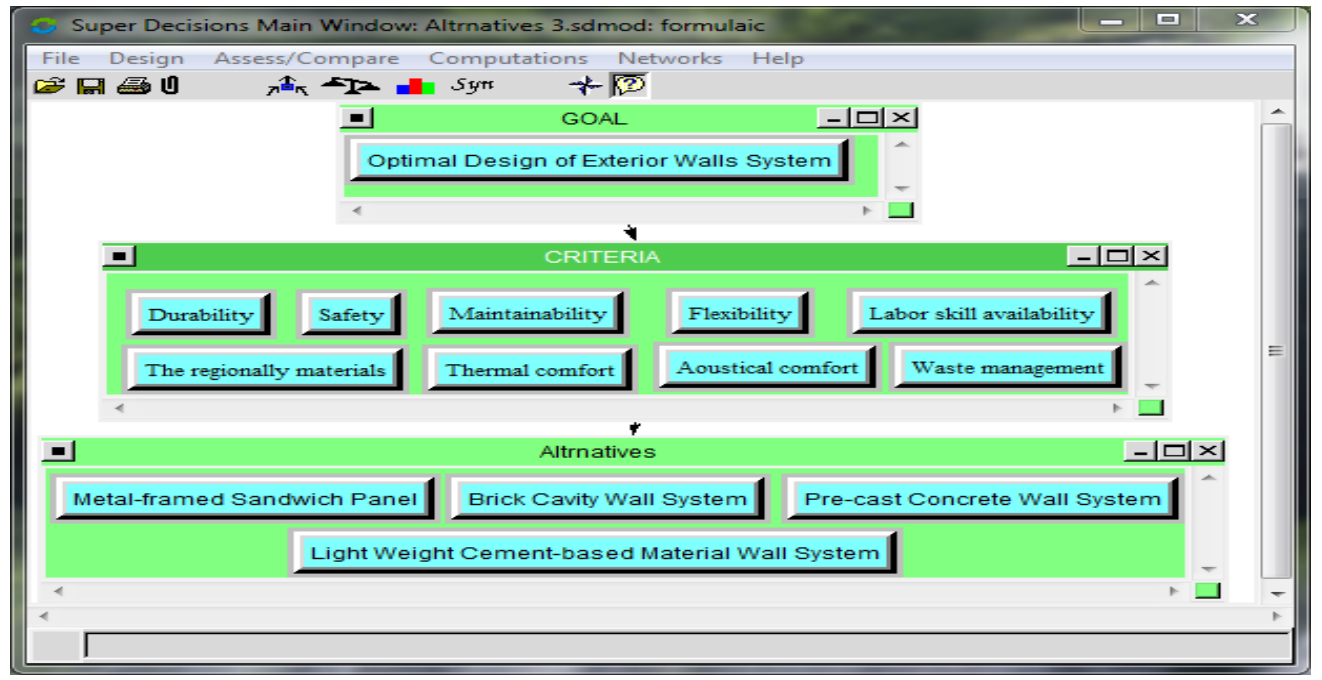

Fig. 7. Hierarchy model for criteria and alternatives

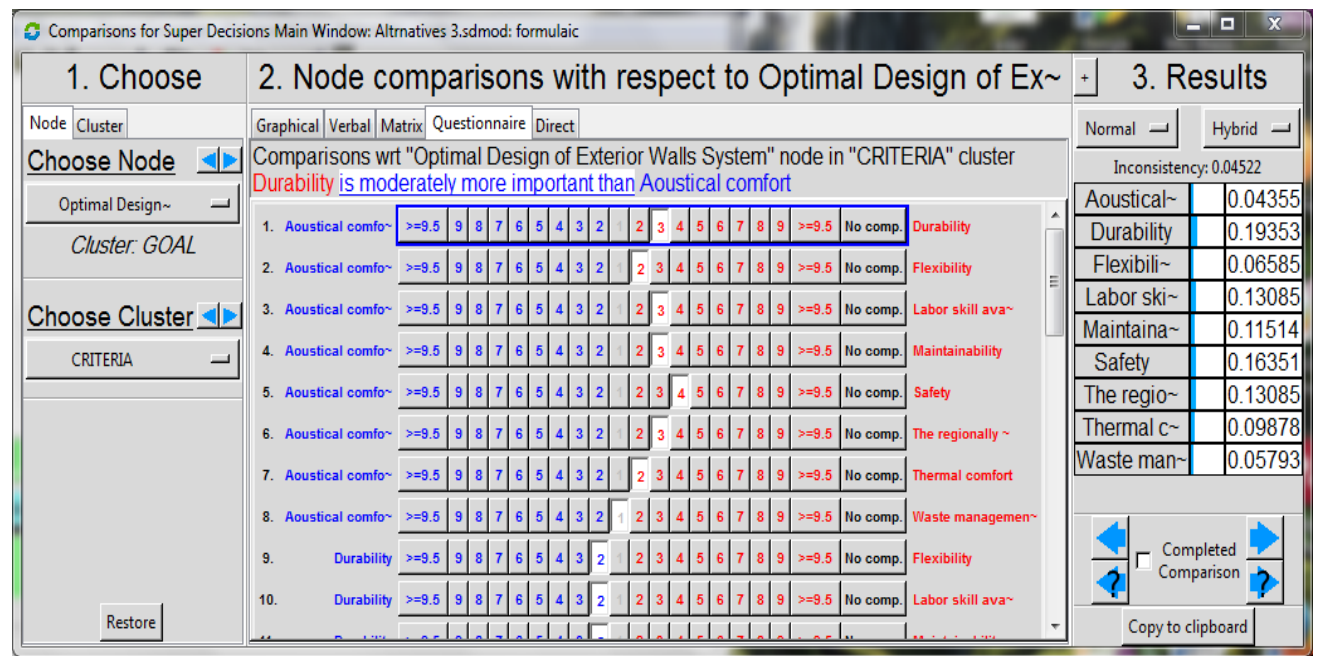

Fig. 8. Pairwise comparisons for criteria with respect to the goal 


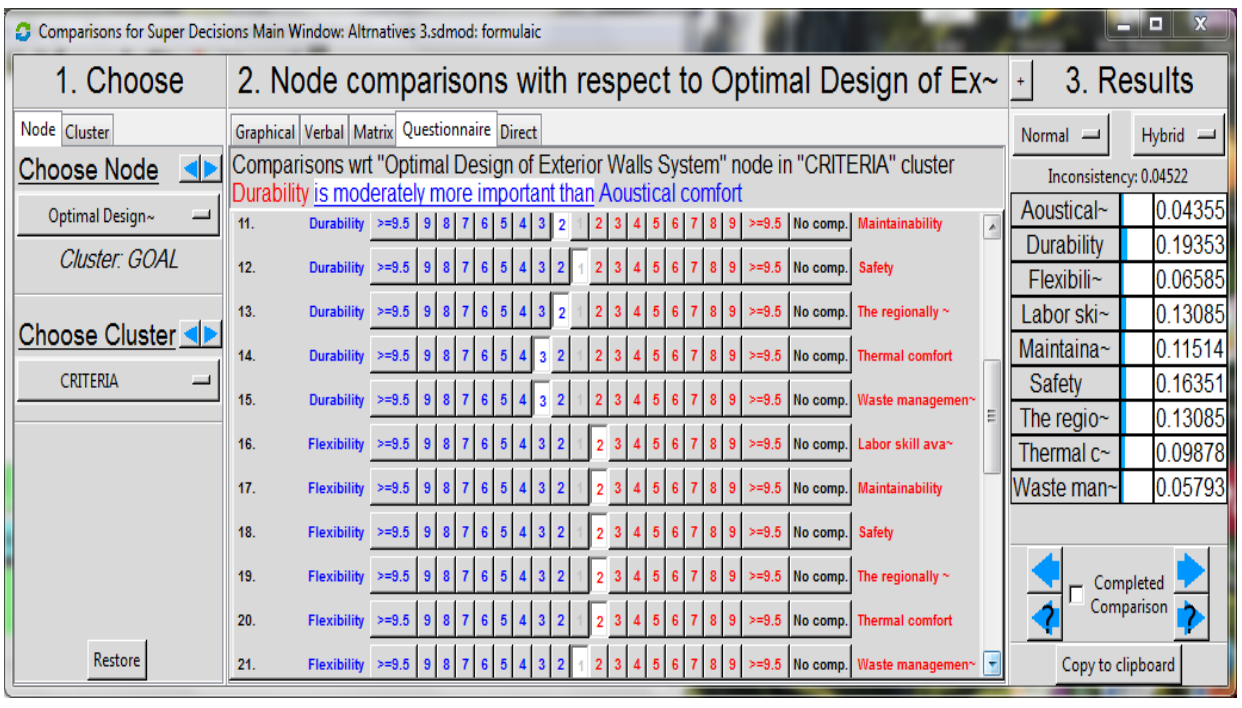

Fig. 8. (Continued) Pairwise comparisons for criteria with respect to the goal

\begin{tabular}{|c|c|c|c|}
\hline \multicolumn{4}{|c|}{ or Super Decisions Main Window: Altrnatives 3.sdmod: formulaic } \\
\hline \multirow{2}{*}{$\begin{array}{l}\text { 1. Choose } \\
\text { Node Cluster }\end{array}$} & \multirow{2}{*}{$\begin{array}{l}\text { 2. Node comparisons with respect to Optimal Design of Ex } \\
\text { Graphical Verbal| Matrix Questionnaire Direct }\end{array}$} & \multicolumn{2}{|c|}{ 3. Results } \\
\hline & & Normal -1 & Hybrid \\
\hline Choose Node $\Delta$ & \multirow{2}{*}{$\begin{array}{l}\text { Comparisons wrt "Optimal Design of Exterior Walls System" node in "CRTTERIA" cluster } \\
\text { Durability is moderately more important than Aoustical comfort }\end{array}$} & \multicolumn{2}{|c|}{ Inconsistency: 0.04522} \\
\hline Optimal Design & & Aoustical & 0.04355 \\
\hline Cluster: GOAL & \multirow{7}{*}{ 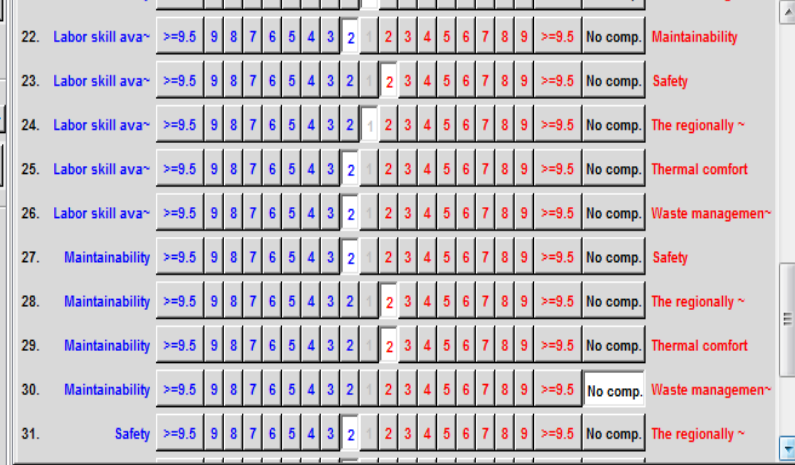 } & & \\
\hline & & 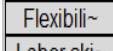 & 0.0 \\
\hline Choose Cluster $\Delta$ & & & \\
\hline CRTERIA & & Safety & 0.16351 \\
\hline & & \begin{tabular}{|l|} 
The regio $\sim$ \\
Thermal $\sim$
\end{tabular} & \begin{tabular}{|l|}
0.13085 \\
0.09878
\end{tabular} \\
\hline & & Waste man & 0.057 \\
\hline & & \multirow{2}{*}{\multicolumn{2}{|c|}{ 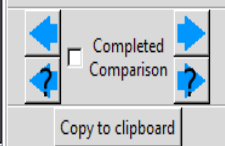 }} \\
\hline & & & \\
\hline
\end{tabular}

Fig. 8. (Continued) Pairwise comparisons for criteria with respect to the goal

\begin{tabular}{|c|c|c|c|}
\hline \multicolumn{4}{|c|}{ or Super Decisions Main Window: Altrnatives 3.sdmod: formulaic } \\
\hline 1. Choose & \multicolumn{3}{|c|}{ 2. Node comparisons with respect to Optimal Design of Ex \pm 3 . Results } \\
\hline Node Cluster & Graphical Verbal| Mattix Questionnaire Direct & Normal - & Hybrid \\
\hline Choose Node 1 & \multirow{2}{*}{$\begin{array}{l}\text { Comparisons wit "Optimal Design of Exterior Walls System" node in "CRITERIA" cluster } \\
\text { Durability is moderately more important than Aoustical comfort } \\
\text { co. cavy inn ava }\end{array}$} & \multicolumn{2}{|c|}{ Inconsistency: 0.04522} \\
\hline Optimal Design $\quad-\quad-\mid$ & & Aoustical & 0.04355 \\
\hline \multirow{2}{*}{ Cluster: GOAL } & \multirow{2}{*}{ 27. Maintainability $\begin{array}{l}y=9.5 \\
\text { 28. }\end{array}$} & Durability & \\
\hline & & Flexibili & \\
\hline Choose Cluster $\Delta$ & \multirow{2}{*}{ 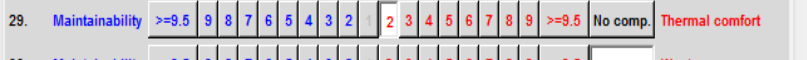 } & Lab & \\
\hline CRITERIA & & Maintaina & 0.115 \\
\hline \multirow[b]{6}{*}{ Restore | } & \multirow{6}{*}{ 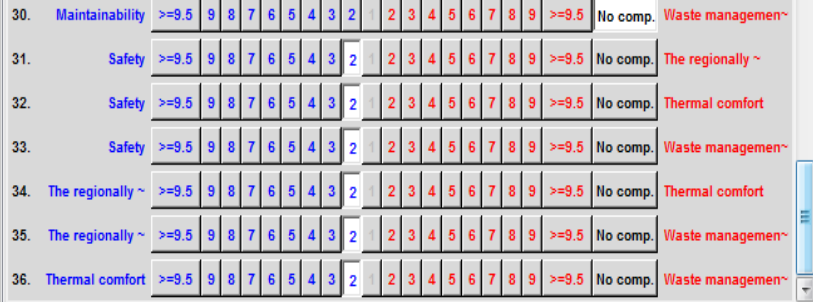 } & ty & 0.16 \\
\hline & & Thermal c & 0.098 \\
\hline & & Waste man- & \\
\hline & & & \\
\hline & & \multicolumn{2}{|c|}{ Comparison } \\
\hline & & \multicolumn{2}{|c|}{ Copy to clipboard } \\
\hline
\end{tabular}

Fig. 8. (Continued) Pairwise comparisons for criteria with respect to the goal 
Completing the required data in the software program has been guided by civil engineers who were specialists in external wall system for buildings.

After the comparison was completed, the whole inconsistency index is less than 0.10 , so the results are fine.

The function index is determined by comparing the alternatives with the main criteria of wall design using the AHP software program. As shown in Fig 9. Then the evaluation matrix is worked out.

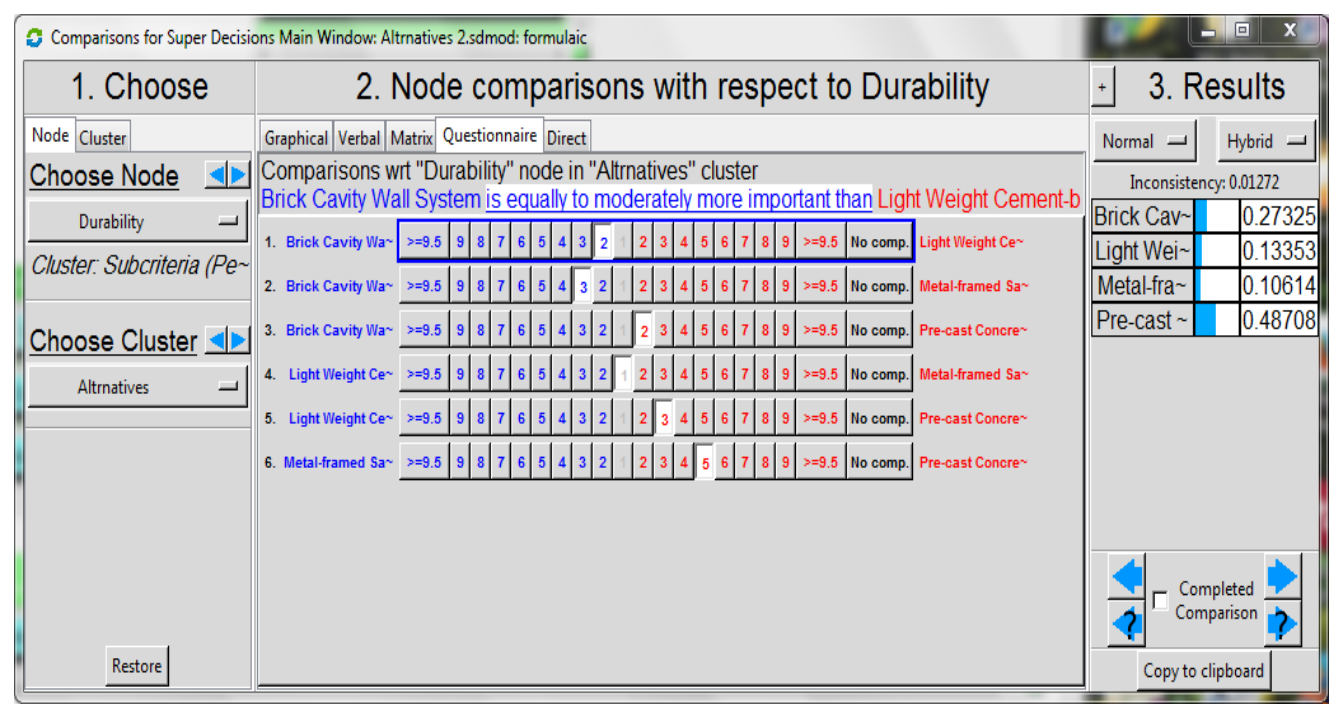

Fig .9. Pairwise comparisons for alternatives with respect to the Durability criteria.

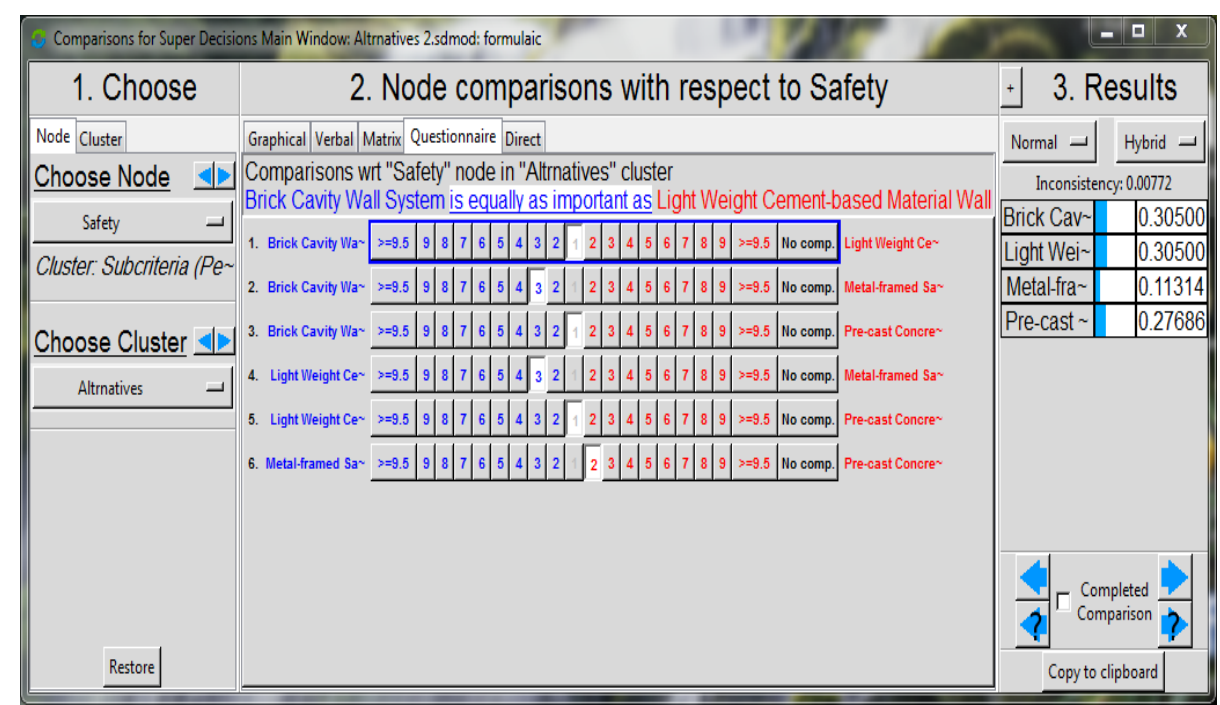

Fig .9. (Continued) Pairwise comparisons for alternatives with respect to the Safety criteria. 


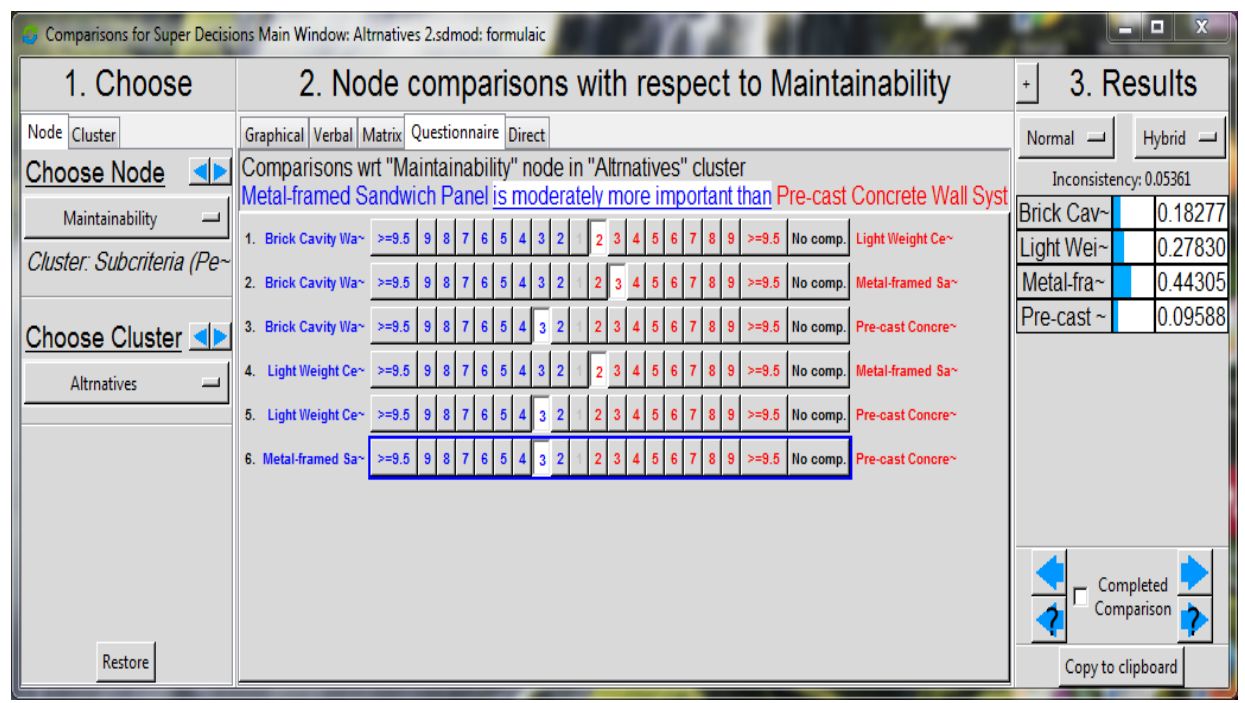

Fig .9. (Continued) Pairwise comparisons for alternatives with respect to the Maintainability criteria.

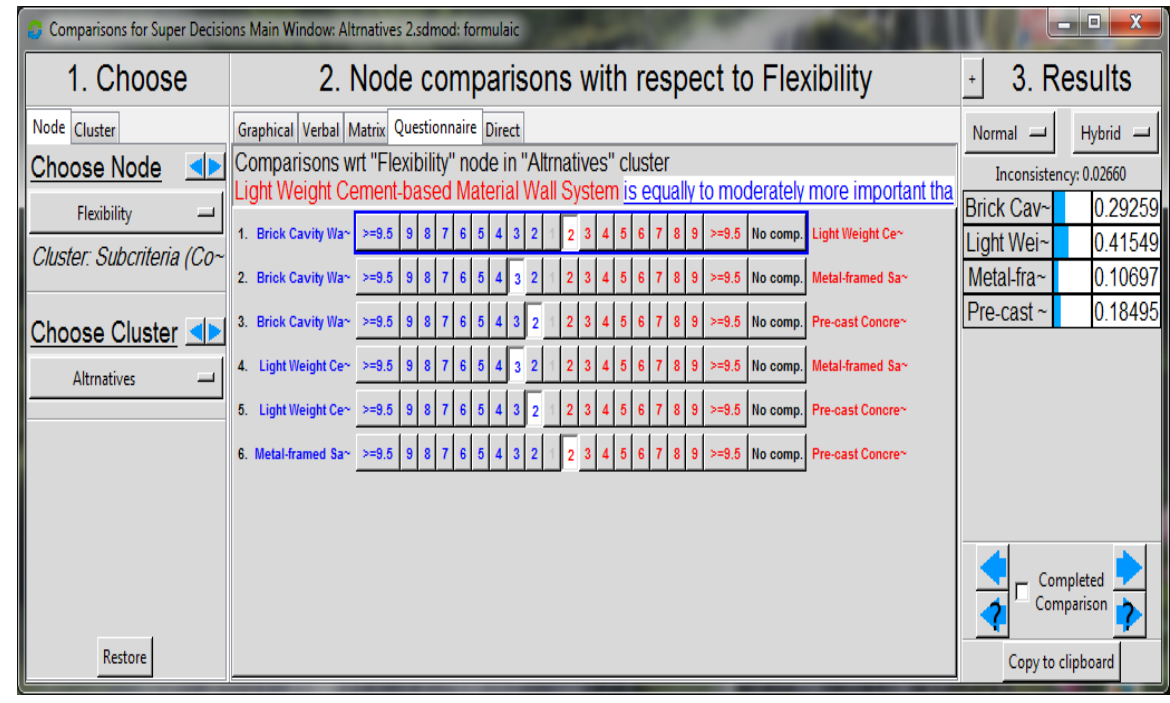

Fig. 9. (Continued) Pairwise comparisons for alternatives with respect to the Flexibility criteria.

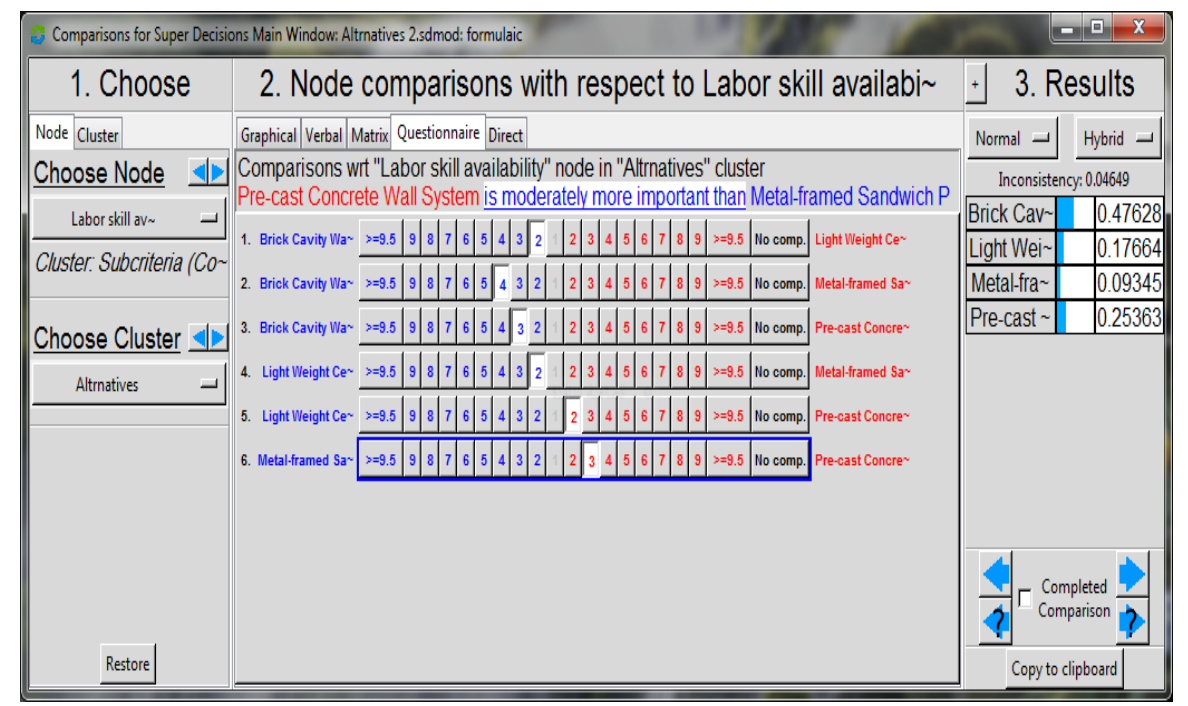

Fig. 9. (Continued) Pairwise comparisons for alternatives with respect to Labor skill availability criteria. 


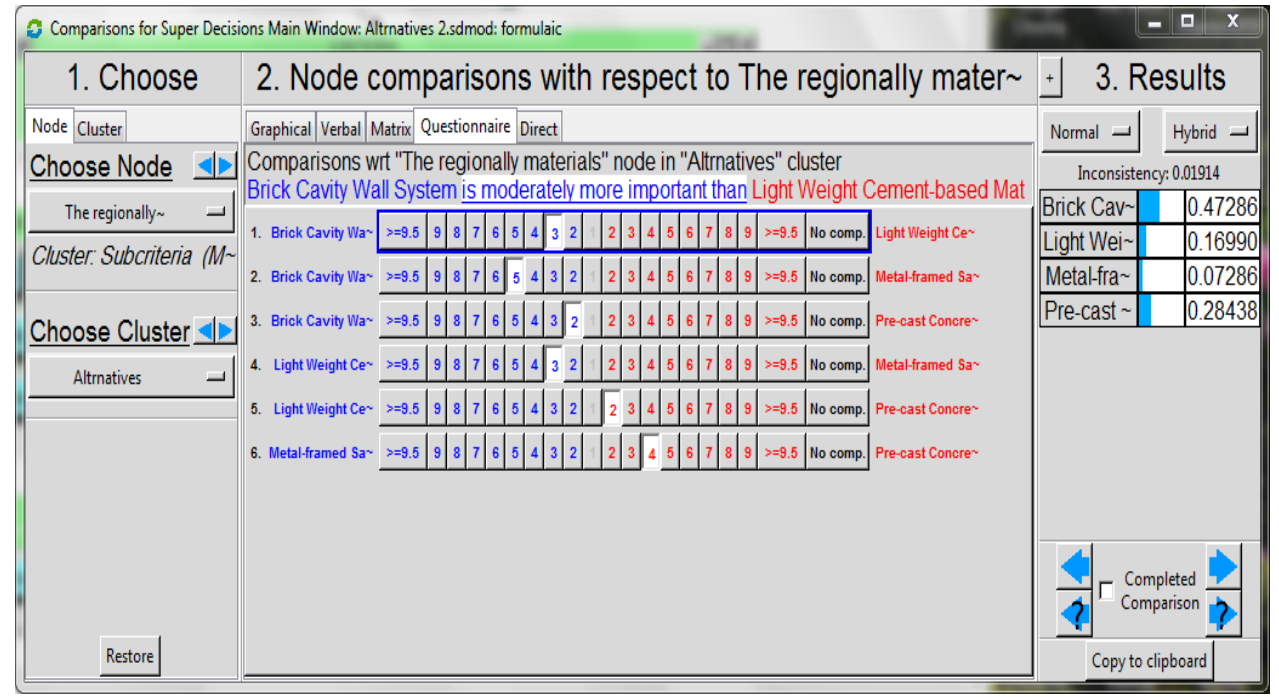

Fig. 9. (Continued) Pairwise comparisons for alternatives with respect to the regionally materials criteria.

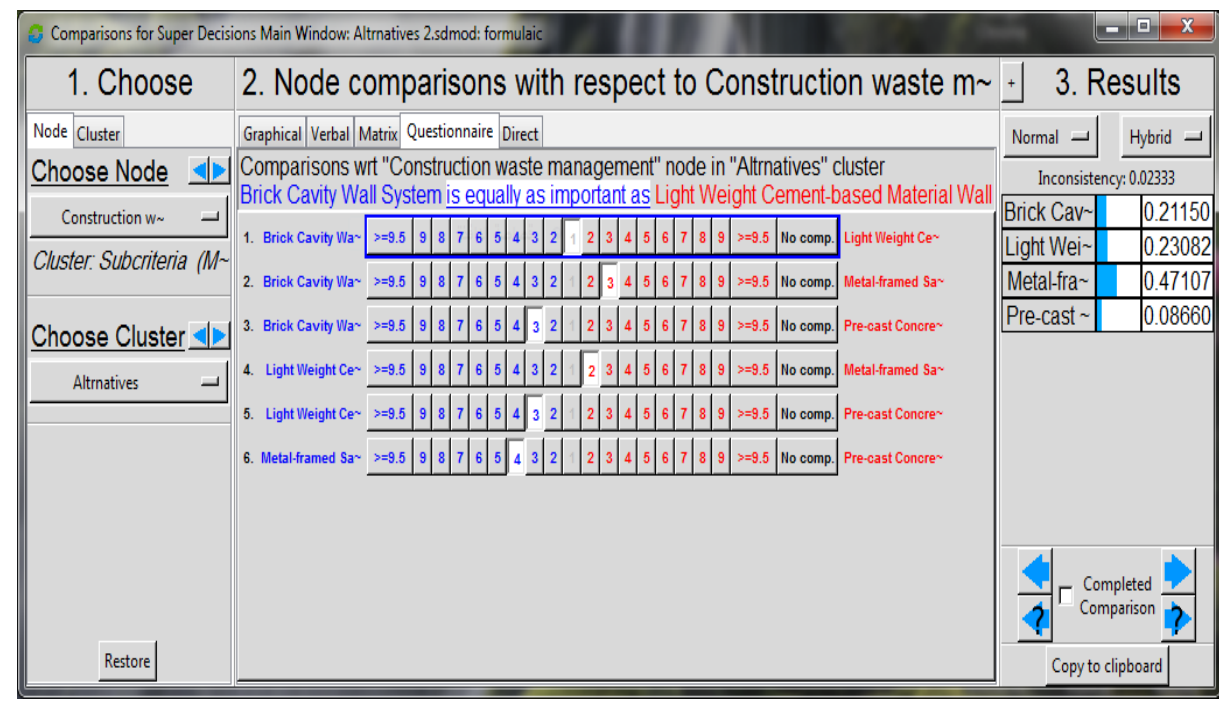

Fig. 9. (Continued) Pairwise comparisons for alternatives with respect to The Waste Management criteria.

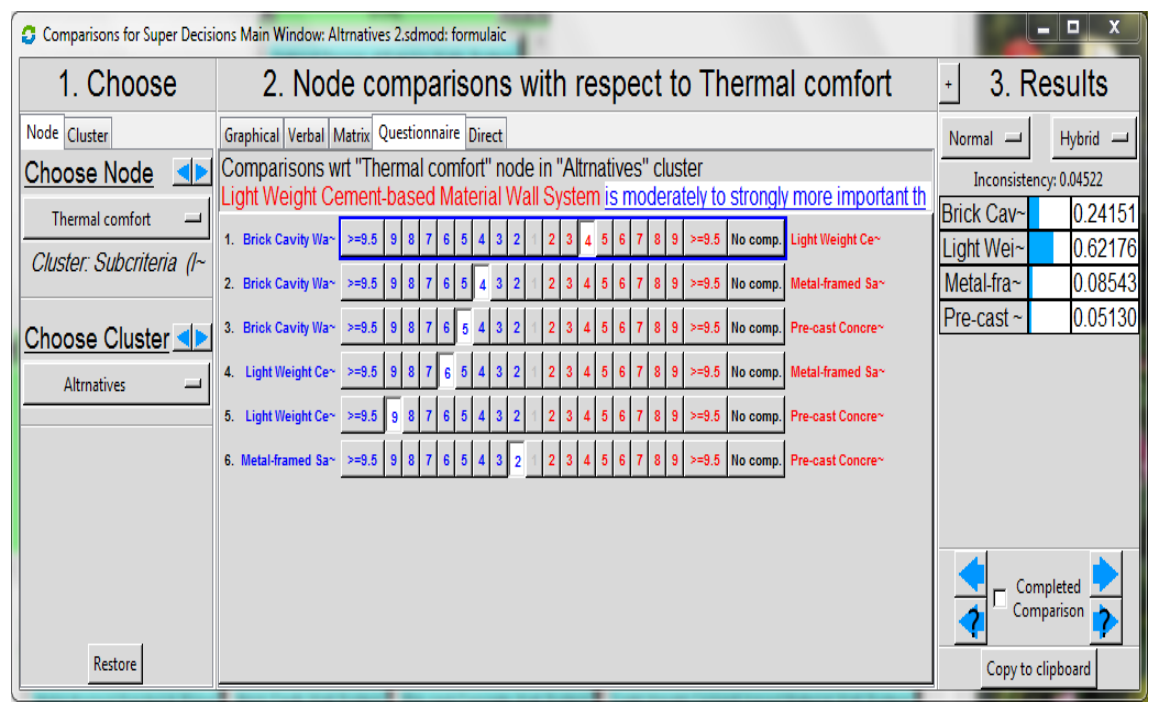

Fig. 9. (Continued) Pairwise comparisons for alternatives with respect to The Thermal properties criteria. 
Table 4 Analysis Matrix

\begin{tabular}{|c|c|c|c|c|c|c|c|c|c|}
\hline \multirow{3}{*}{ Evaluation criteria } & \multirow{3}{*}{$\begin{array}{l}\text { Assigned } \\
\text { weight }\end{array}$} & \multicolumn{8}{|c|}{ ALTERNATIVES } \\
\hline & & \multicolumn{2}{|c|}{$\begin{array}{c}\text { Brick } \\
\text { Cavity } \\
\text { Wall System }\end{array}$} & \multicolumn{2}{|c|}{$\begin{array}{l}\text { Light Weight } \\
\text { Block } \\
\text { Wall System }\end{array}$} & \multicolumn{2}{|c|}{$\begin{array}{c}\text { Precast } \\
\text { Concrete } \\
\text { Wall Panel }\end{array}$} & \multicolumn{2}{|c|}{$\begin{array}{c}\text { Metal-framed } \\
\text { sandwich panel Wall } \\
\text { System }\end{array}$} \\
\hline & & Ranking & Score & Ranking & Score & Ranking & Score & Ranking & Score \\
\hline Durability & 0.194 & 0.270 & 0.052 & 0.130 & 0.025 & 0.490 & 0.095 & 0.110 & 0.021 \\
\hline Safety & 0.164 & 0.310 & 0.051 & 0.310 & 0.051 & 0.280 & 0.046 & 0.110 & 0.018 \\
\hline Maintainability & 0.115 & 0.180 & 0.021 & 0.280 & 0.032 & 0.100 & 0.012 & 0.440 & 0.051 \\
\hline Flexibility & 0.066 & 0.290 & 0.019 & 0.420 & 0.028 & 0.180 & 0.012 & 0.110 & 0.007 \\
\hline $\begin{array}{l}\text { Labor skill } \\
\text { availability }\end{array}$ & 0.131 & 0.480 & 0.063 & 0.180 & 0.024 & 0.250 & 0.033 & 0.090 & 0.012 \\
\hline $\begin{array}{l}\text { The regionally } \\
\text { materials }\end{array}$ & 0.131 & 0.470 & 0.061 & 0.170 & 0.022 & 0.280 & 0.037 & 0.070 & 0.009 \\
\hline Waste Management & 0.058 & 0.210 & 0.012 & 0.230 & 0.013 & 0.090 & 0.005 & 0.470 & 0.027 \\
\hline Thermal properties & 0.099 & 0.240 & 0.024 & 0.620 & 0.061 & 0.050 & 0.005 & 0.090 & 0.009 \\
\hline $\begin{array}{l}\text { Acoustical } \\
\text { properties }\end{array}$ & 0.044 & 0.330 & 0.014 & 0.040 & 0.002 & 0.480 & 0.021 & 0.060 & 0.003 \\
\hline Total weight & $\begin{array}{l}\text { Score }=\text { Weight } * \\
\text { Ranking }\end{array}$ & & & 0.2 & & & & 0.1 & \\
\hline
\end{tabular}

\section{Conclusions}

The evaluation matrix resulted in prioritization of four alternatives among a wide range of alternatives to exterior wall systems in school buildings. They are, in the order of preference: Brick Cavity Wall System, Precast

Concrete Wall, Light Weight Block Wall System and Metal-framed sandwich panel Wall System.

This proposed method should help designers and decision maker to select the best external wall system for any particular situation.
In addition, this method can be used for evaluation and choose any construction system by following the value engineering methodology as shown in this paper

\section{References}

1. Dell ‘ Isola , R.S. Means , USA ,1997.

2. Saaty, T. L. , Int. J Service Science, Vol.1 ,No.1, 2008.

3. Abudlmohsen Al-Hammad, M.A., Journal of Architectural Engineering , volume: 2, No.3 , September, 1996.

4. Department of Public Works LEED Certification fact sheet_alt layout.doc , USA , 2007. 